\title{
PHOTOTHERAPEUTIC KERATECTOMY FOR RECURRENT CORNEAL EROSIONS
}

\author{
DAVID P. S. O'BRART, MALCOLM G. KERR MUIR and JOHN MARSHALL \\ London
}

\begin{abstract}
SUMMARY
Recurrent corneal erosion may be a difficult disorder to treat, with a number of patients suffering persistent symptoms despite conventional therapy. We present a series of 15 patients (17 eyes) who underwent excimer laser phototherapeutic keratectomy (PTK) for recurrent corneal erosion. In 9 patients a previous episode of corneal trauma could be identified, while in 6 ( 8 eyes) the problem had occurred spontaneously. The mean duration of symptoms prior to PTK was 13 months (range 6-60 months). All patients had received lubricant ointments, 7 had tried bandage contact lenses and 4 had undergone epithelial debridement with no amelioration of their symptoms. The affect area of epithelium was removed and a 20-30 pulse (5-7 $\mu \mathrm{m})$ ablation was performed to Bowman's membrane. Great care was taken to avoid the edges of treatment zones from encroaching on the axial cornea. In 11 patients (13 eyes) there was a marked improvement in symptoms post-operatively with no recurrences. The mean follow-up was 11 months (range 6-24 months). Four patients experienced recurrent episodes 3-6 months after PTK and 2 have subsequently been retreated, 1 of whom has been symptom-free for 12 months. Post-operative best corrected visual acuity was unaltered in 9 eyes and improved by at least one Snellen line in 8 eyes. Excimer laser PTK appears to be a safe and promising procedure for recurrent corneal erosion in cases refractory to medical treatment. Further studies are indicated to compare its effectiveness with established surgical procedures.
\end{abstract}

Recurrent corneal epithelial erosion was first described in 1872 by Hansen. ' Typically, the patient experiences episodes of acute symptoms of pain, lacrimation and photophobia on waking. These may occur following corneal trauma or spontaneously, when they are thought to be associated with epithelial basement membrane degeneration. ${ }^{2-11}$ During the acute stage an area of raised or loose epithelium is often identified. The symptoms usually

Correspondence to: Mr D. P. S. O’Brart, FRCS. FRCOphth, United Medical and Dental Schools, Department of Ophthalmology. St. Thomas' Hospital, Lambeth Palace Road, London SE1 7EH, UK. resolve rapidly and when the patient presents to the ophthalmologist few clinical signs may be present. Subsequent recurrences may take place at intervals of a few weeks or months over a period of years. Although most cases respond to conventional medical therapy with lubricant ointments, ${ }^{11}$ hypertonic saline or soft contact lenses, ${ }^{12.13}$ the condition may occasionally be refractory to such treatment.

Surgical intervention was first reported over a century ago, ${ }^{2-4}$ but was largely superseded by chemical cauterisation. ${ }^{5,6}$ In the 1960 s and 1970 s medical therapy became the mainstay of treatment. Over the past decade surgical intervention has regained popularity. Epithelial basement membranectomy has been recommended for cases associated with epithelial basement membrane degeneration, while anterior stromal micropuncture has been suggested for traumatic recurrent corneal erosion. ${ }^{14-17}$

During the mid 1980s clinical excimer lasers became available and offered a new approach to the treatment of superficial corneal pathologies. ${ }^{18}$ The advantages of such lasers derive from two unique characteristics. The first is the ability to remove corneal tissue with extreme precision and minimal adjacent tissue damage. ${ }^{19-22}$ The second is the large beam cross-sections, typically several millimetres in diameter, which allow simultaneous treatment of wide areas.

Following extensive laboratory investigations, clinical studies to evaluate the potential of excimer lasers in treating corneal pathology were conducted. Initially treatment was directed at removing superficial axial opacities or smoothing surface irregularities, ${ }^{18.23-27}$ the former resulting in an improvement in visual performance ${ }^{18,23-26}$ and the latter producing increased ocular comfort ${ }^{18}$ or allowing the use of contact lenses. ${ }^{25 \cdots 27}$

Subsequently, a number of centres, including our own, began to evaluate the role of excimer laser photoablation in the treatment of recurrent corneal erosion. Dausch et $a l .^{28}$ recently reported a series of 74 eyes in which 55 (74\%) were recurrence free post-operatively. All their cases were post-traumatic and treated with a laser with a 
radiant exposure at the cornea of $800 \mathrm{~mJ} / \mathrm{cm}^{2}$, which is very much higher than that for refractive surgery. We report our experience with excimer laser phototherapeutic keratectomy (PTK) for recurrent corneal erosion in a series of 17 eyes treated since January 1991. These cases included both epithelial basement membrane dystrophies and post-traumatic aetiologies. We discuss our surgical technique and suggest possible mechanisms of action of PTK in the treatment of this condition.

\section{MATERIALS AND METHODS}

\section{Excimer Laser}

A Summit Technology UV200 excimer laser was used until July 1993 and thereafter a Summit Technology OmniMed excimer. Both systems had a spectral emission at $193 \mathrm{~nm}$. The pulse energy resulted in a radiant exposure of 180 $\mathrm{mJ} / \mathrm{cm}^{2}$ and the pulse frequency was fixed at $10 \mathrm{~Hz}$. The beam configuration was circular in cross-section, with fixed diameters, selected to be between 1.0 and $5.0 \mathrm{~mm}$ in the UV200 laser and between 1.0 and $6.5 \mathrm{~mm}$ in the OmniMed system.

\section{Subjects}

There were 15 patients (17 eyes) who underwent excimer laser PTK for recurrent corneal erosion (Table I). The mean age at presentation was 43 years (range 24-63 years). Eleven patients were female and 4 were male. The individual patient details are shown in Table I.

\section{Assessment and Examination}

Patients were fully counselled prior to surgery to discuss its investigative nature. A full ocular and medical history was taken and a detailed ocular examination performed, including where possible a full refraction. All patients reported the classic symptoms of corneal erosion syndrome, with episodes of pain, photophobia and lacrimation on waking. In 9 patients a previous episode of corneal trauma could be identified, while in 6 ( 8 eyes treated) the problem had occurred spontaneously. All patients with spontaneous recurrent erosions had bilateral symptoms. The mean duration of symptoms prior to PTK was 13 months (range 6-60 months).

All patients had received non-hyperosmotic lubricant ointments, 7 had tried bandage contact lenses and 4 had undergone epithelial debridement with no amelioration of their symptoms.

There were 4 patients who were treated during an acute episode of recurrent erosion, in which a loose area of epithelium could be easily delineated. In all the remaining patients areas of corneal epithelial abnormalities could be detected. These included regions of elevated epithelium, microcysts, epithelial fingerprints and zones of faint subepithelial opacity (Fig. 1).

\section{Surgical Technique}

A local anaesthetic (amethocaine $\mathrm{HCl} \mathrm{1 \% )} \mathrm{was} \mathrm{instilled.}$ The patient was put in a supine position under the laser and taught to fixate on the target light for the predicted duration of the procedure. The noise associated with the laser was demonstrated to the patient and they were warned to expect a smell of burning during treatment. A lid speculum was then inserted.

Table I. Patient data

\begin{tabular}{|c|c|c|c|c|c|c|c|c|}
\hline $\begin{array}{l}\text { Patient } \\
\text { no., age } \\
\text { (yr) and } \\
\text { sex }\end{array}$ & Side & Aetiology & $\begin{array}{l}\text { Duration of } \\
\text { symptoms } \\
\text { (months) }\end{array}$ & Previous treatments & $\begin{array}{l}\text { Pre-op. } \\
\text { refraction }\end{array}$ & $\begin{array}{l}\text { Post-op. } \\
\text { refraction }\end{array}$ & Outcome & $\begin{array}{l}\text { Follow-up } \\
\text { (months) }\end{array}$ \\
\hline $1.49 \mathrm{~F}$ & $\mathrm{~L}$ & Spontaneous & 8 & $\begin{array}{l}\text { Lubricants, bandage lenses, } \\
\text { epithelial debridement }\end{array}$ & $6 / 6$ with pinhole & $6 / 6-0.75 /-1.00 \times 90$ & No recurrences & 24 \\
\hline & $\mathrm{R}$ & Spontaneous & 6 & Lubricants, bandage lenses & $6 / 12$ with pinhole & $6 / 9$ unaided & No recurrences & 18 \\
\hline $2.55 \mathrm{M}$ & $\mathrm{L}$ & $\begin{array}{l}\text { Spontaneous } \\
\text { (Cogan’s) }\end{array}$ & 12 & Lubricants & $6 / 9$ & $6 / 9$ & No recurrences & 9 \\
\hline $3.36 \mathrm{~F}$ & $\mathrm{~L}$ & Traumatic & 18 & Lubricants & $6 / 6$ plano & $6 / 5-0.25 /-1.00 \times 50$ & No recurrences & 18 \\
\hline $4.37 \mathrm{~F}$ & $\mathrm{R}$ & Traumatic & 18 & Lubricants, bandage lenses & $6 / 9$ plano & $6 / 5-0.5 \mathrm{D}$ & No recurrences & 18 \\
\hline $5.40 \mathrm{M}$ & $\mathrm{R}$ & Traumatic & 6 & Lubricants, bandage lenses & $6 / 6$ plano & $6 / 5-0.75 /-1.00 \times 180$ & $\begin{array}{l}\text { No, recurrences, ghosting } \\
\text { at night }\end{array}$ & 18 \\
\hline $6.50 \mathrm{~F}$ & $\mathrm{R}$ & Traumatic & 9 & Lubricants & $6 / 18+1.00 /-2.00 \times 70$ & $6 / 60.00 /-1.00 \times 120$ & No recurrences & 9 \\
\hline $7.63 \mathrm{~F}$ & $\mathrm{~L}$ & Traumatic & 9 & $\begin{array}{l}\text { Lubricants, bandage lenses, } \\
\text { epithelial debridement }\end{array}$ & $6 / 9+1.75 /-0.25 \times 90$ & $6 / 9+1.75 /-1.25 \times 120$ & No recurrences & 6 \\
\hline $8.28 \mathrm{~F}$ & $\mathrm{~L}$ & Traumatic & 12 & Lubricants & $6 / 5+0.25$ & $6 / 5-1.00 /-0.5 \times 20$ & No recurrences & 9 \\
\hline $10.36 \mathrm{M}$ & $\mathrm{L}$ & Spontaneous & 6 & $\begin{array}{l}\text { Lubricants, epithelial } \\
\text { debridement }\end{array}$ & $6 / 90.00 /-0.50 \times 180$ & $6 / 6-1.00 /-0.5 \times 80$ & No recurrences & 6 \\
\hline $11.24 \mathrm{M}$ & $\mathrm{R}$ & Traumatic & 4 & Lubricants & NPL & NPL & No recurrences & 6 \\
\hline $12.40 \mathrm{~F}$ & $\mathrm{R}$ & Traumatic & 60 & $\begin{array}{l}\text { Lubricants, bandage lenses, } \\
\text { epithelial debridement }\end{array}$ & $6 / 9$ with pinhole & $6 / 9+0.5 /-1.00 \times 20$ & $\begin{array}{l}\text { Recurrence at } 6 \text { months } \\
\text { retreated, no episodes } \\
\text { since }\end{array}$ & $24(12)^{a}$ \\
\hline $13.62 \mathrm{~F}$ & $\mathrm{R}$ & Spontaneous & 12 & Lubricants, bandage lenses & $6 / 9-2.75 /-0.5 \times 15$ & $6 / 9$ with pinhole & $\begin{array}{l}\text { Recurrence at } 4 \text { months } \\
\text { retreated, no episodes } \\
\text { since }\end{array}$ & $7(3)^{a}$ \\
\hline $14.57 \mathrm{~F}$ & $\mathrm{~L}$ & Spontaneous & 6 & Lubricants & $6 / 9-1.00 /-1.25 \times 180$ & $6 / 9-1.00 /-1.00 \times 30$ & $\begin{array}{l}\text { Recurrence at } 3 \text { months } \\
\text { not retreated }\end{array}$ & 6 \\
\hline $15.36 \mathrm{~F}$ & $\mathrm{R}$ & Traumatic & 12 & Lubricants & $6 / 9-5.50 /-1.25 \times 10$ & $6 / 9-5.00 /-1.25 \times 20$ & $\begin{array}{l}\text { Recurrence at } 6 \text { months } \\
\text { not retreated }\end{array}$ & 9 \\
\hline
\end{tabular}

${ }^{a}$ Follow-up after re-treatment. 

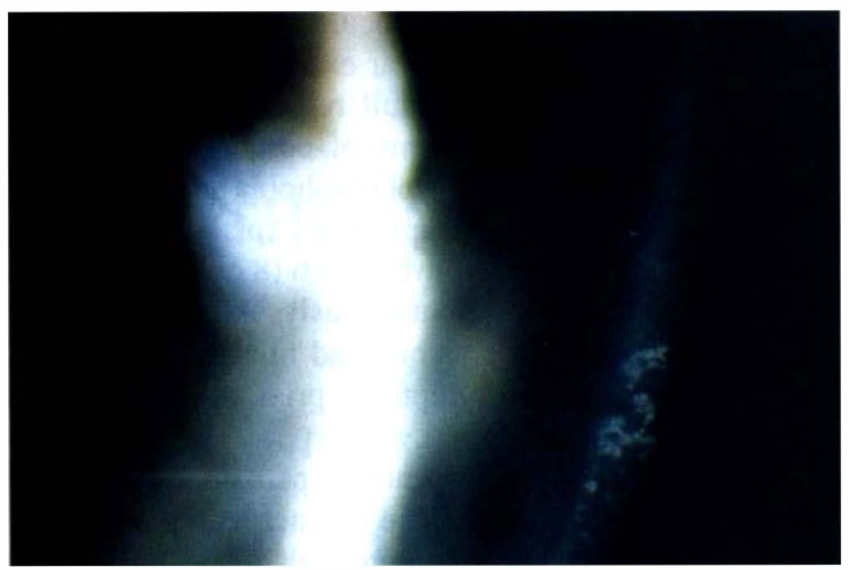

Fig. 1. The right eye of a 37-year-old woman (patient 4) with recurrent corneal erosion following a corneal abrasion from a fingernail injury 18 months previously. There are a number of intraepithelial microcysts seen inferiorly. This patient had been treated with lubricants and bandage contact lenses with no amelioration of her symptoms. Following PTK she has been symptom-free for 18 months.

The area of loose or abnormal epithelium was gently but meticulously removed using a moist weck cell sponge and/or a \#64 beaver blade. In eyes where the zone of denuded epithelium partially encroached over the entrance pupil, residual epithelium was completely removed from over this area. This allowed the central cornea to be treated with a single large $(5.0-6.5 \mathrm{~mm})$ ablation zone and to avoid the edges of treatment zones encroaching on the axial cornea, as this might produce irregular astigmatism (Fig. 2). A 20-30 pulse (5-7 $\mu \mathrm{m})$ ablation was then performed to Bowman's membrane. The spot sizes used on the peripheral cornea were determined by the area of the abnormality to be treated. In eyes with epithelial basement membrane degeneration where virtually all of the corneal epithelium was abnormal and therefore
A)

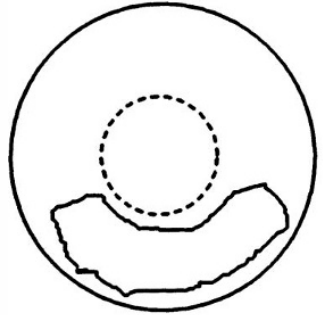

C)

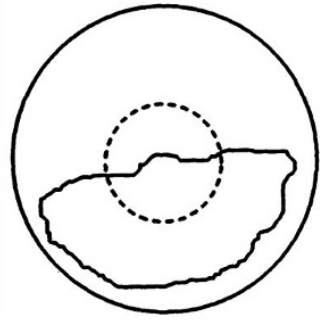

B)

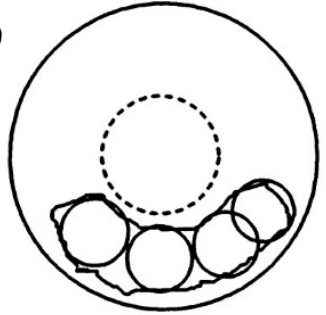

D)

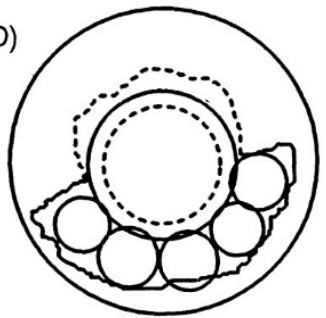

Fig. 2. The affected epithelium is removed ( $A$ ) and a 20-30 pulse ablation is performed to Bowman's membrane $(B)$. In eyes where the zone of denuded epithelium partially encroaches over the entrance pupil $(C)$, residual epithelium is removed from this area and the axial cornea treated with a single large ablation zone, followed by treatment to the periphery $(D)$. removed, paralimbal areas were deliberately left untreated.

\section{Post-operative Management}

Post-operatively a mydriatic (homatropine $2 \%$ ) and an antibiotic ointment (chloramphenicol 1\%) were instilled and the eye padded for 24 hours. Oral analgesics were prescribed for the first 48 hours and chloramphenicol $0.5 \%$ eye drops were administered four times a day for 10 days. The majority of patients were followed up 1 week, at 1,3 , 6, 9 and 12 months, and annually thereafter.

A full refraction and slit lamp biomicroscopical examination were performed at each post-operative visit. Corneal topography was examined using a photokeratoscope (TMS-1 Topographic Modelling System, Computed Anatomy).

\section{RESULTS}

The results for individual patients are shown in Table I. All patients experienced ocular pain during the first 24 to 48 hours post-operatively. All eyes were re-epithelialised within 6 days.

In 13 eyes (patients 1-11) there was a marked improvement in symptoms post-operatively with no recurrent episodes. The mean follow-up was 11 months (range 6-28 months). Four subjects (patients 12-15) experienced recurrent symptoms 3-6 months after PTK, of whom 2 have been retreated. One of these retreated eyes has been symptom-free for 12 months (patient 12) and the other for 3 months (patient 13). The remaining 2 individuals were treated with antibiotics and padding during the acute stage and then with non-hypersomotic lubricants at night. They have both been symptom-free for over 3 months (patients 14 and 15).

Best corrected visual acuity was unaltered in 9 eyes and improved by at least one Snellen line in 8 eyes. Full preand post-operative refractive data were available in 11 of the 17 eyes. There was no statistically significant difference between the pre-operative and 6 month

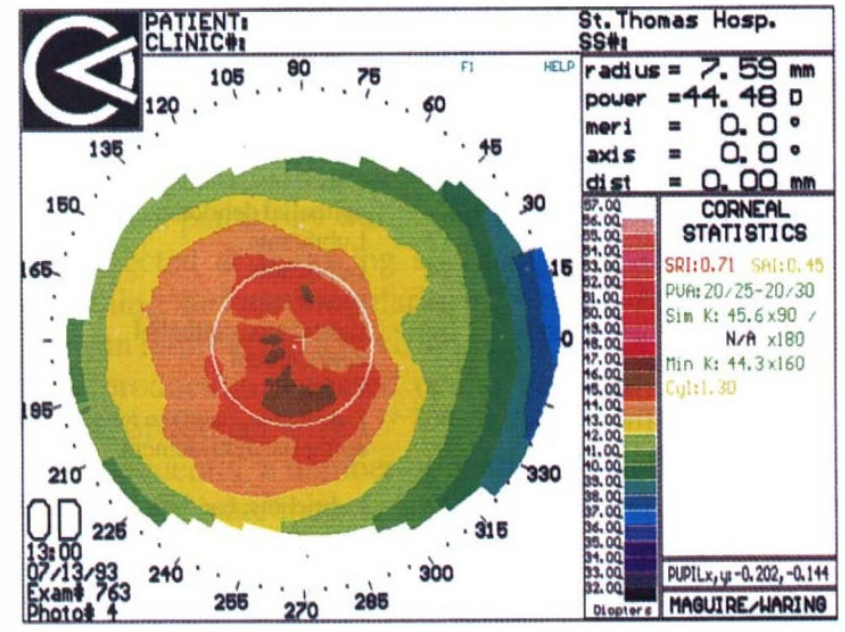

Fig. 3. Corneal topography 9 months after successful PTK of the eye of patient 5 . The cornea is regular with no topographical evidence of the multiple ablations used to treat this eye. 
post-operative manifest reaction in these 11 cases. However, in 7 eyes (patients 3-8 and 10) a myopic shift of greater than -0.5 dioptres and up to -1.25 dioptres persisted 6 months after PTK. All eyes appeared to have regular corneal topography at 6 months with no apparent topographical evidence of the ablation zones or surface irregularities (Fig. 3).

A faint subepithelial haze appeared in 5 eyes 3 months after laser ablation. All treated eyes had clear corneas 6 months after treatment, except in 1 patient where preoperative anterior stromal scars persisted (patient 9).

One patient with large pupils complained of ghosting effects at night (patient 5). Topography of this patient's cornea was entirely normal with no evidence of central corneal flattening (Fig. 3).

\section{DISCUSSION}

On the basis of our experience and that of other centres throughout the world, excimer laser PTK appears to offer great potential in the treatment of cases of recurrent corneal epithelial erosion which are refractory to treatment with conventional medical therapy. The overall success rate in our patient group was $76 \%$, which is similar to those of Dausch et al. $(74 \%)^{28}$ and Fagerhom et al. $(84 \%)^{25}$

Complications were minimal and this must reflect the limited ablation depths $(5-7 \mu \mathrm{m})$ used to treat these eyes. Bowman's membrane is approximately $12 \mu \mathrm{m}$ thick $^{29}$ and therefore all our PTK treatments should have been effected within Bowman's membrane and not beyond it. The disturbances in corneal transparency that have been reported after photorefractive keratectomy $(\mathrm{PRK})^{30}$ did not occur in these eyes. There was only the slightest trace of subepithelial haze during the first 3 months in 5 eyes and this rapidly improved. We found no evidence of disturbances in corneal transparency associated with the photoablative treatment persisting 6 months after surgery. Corneal topography revealed no abnormalities and best corrected visual acuity was either unaltered or improved post-operatively.

One patient complained of ghosting effects at night (patient 5). These may be associated with excursions of the pupil margins beyond the edges of the treated $(5.00$ $\mathrm{mm}$ ) area on the central cornea. Such phenomena have been reported after PRK for myopia. ${ }^{31}$ However, topography of this patient's cornea was entirely normal with no evidence of central corneal flattening or surface irregularities (Fig. 3). In view of this and the minimal tissue ablation required for the treatment of his eye compared with that for PRK, it is difficult to explain his symptomatology.

Previous reports of PTK have demonstrated a hyperopic shift in refraction post-operatively. ${ }^{18.26}$ This has been associated with axial ablations to remove anterior stromal pathology and ablation depths many times greater than that used in the treatment of recurrent erosions. Our study showed that there was no statistically significant difference between the pre- and post-operative manifest refrac- tion. This again probably reflects the very limited amounts of tissue ablated from the stromal surface. An interesting observation in some of our patients was a small myopic shift in refraction. This may represent a slight steepening in the cental cornea due to peripheral stromal ablation. However, there was no topographical evidence of this and in view of the minimal amounts of tissue removed this explanation seems improbable. It is more likely to be due to a change in epithelial thickness of refractive index as a consequence of photoablation or as a result of an improvement in epithelial stability.

Over the past decade anterior stromal micropuncture has been advocated for the treatment of recalcitrant recurrent erosions. ${ }^{15-17}$ This technique involves puncturing the affected epithelium and underlying stroma with a hyperdermic needle ${ }^{15-17}$ or a Nd:YAG laser. ${ }^{32}$ These microincisions bring the corneal epithelium in direct contact with the stroma, which results in the synthesis of new epithelial basement membrane and a strong adhesion with the stroma. ${ }^{33}$ The procedure is simple to perform at very low cost and appears to have a high success rate. ${ }^{15-17,32}$ However, anterior stromal scars are associated with the puncture sites and may affect visual acuity in extensive axial treatment. There is a risk of localised endothelial damage and corneal perforation, especially with small-gauge needles. ${ }^{33}$ The minute amount of precise tissue removal and maintenance of corneal transparency may allow excimer laser PTK to produce more satisfactory results.

The mechanism of action of excimer photoablation in the treatment of recurrent erosion is unknown. It was the experience with PRK that first suggested a possible role for photoablation in the treatment of recurrent erosion. Despite the creation of an iatrogenic corneal abrasion as part of the PRK procedure, long-term problems with epithelial instability do not occur. A few patients may complain of ocular discomfort on waking, which usually settles a few months after surgery. ${ }^{34}$ Very occasionally a patient may experience a single episode of epithelial breakdown several weeks post-operatively, but recurrent episodes do not occur. ${ }^{34}$ In our experience of over 600 PRK treatments since February 1990 we have not identified any patients with recurrent corneal erosion and this appears to be persistent with the findings of other research groups. ${ }^{35}$ Histological studies of excimer-laser-ablated monkey corneas have shown an increased accumulation of type VII collagen (a major component of anchoring fibrils) and hemidesmosomes along the basement membrane of the basal epithelial cells. ${ }^{36.37}$ Human studies have indicated that the basal epithelial layer forms hemidesmosomes and new basement membrane within 2 weeks of photoablation. ${ }^{30}$ In addition, there appear to be undulations and excursions of stromal collagen, as large as $4 \mu \mathrm{m}$, into the basal epithelial layer. ${ }^{30}$ These are most noticeable on the edge of the ablated zone. Such undulations would greatly increase the surface area of attachment. Thus new hemidesmosomes, anchoring fibrils and epithelial basement membrane are synthesised rapidly and in increased amounts after PRK and problems with epi- 
thelial instability would therefore not be expected. Indeed, in those patients who are re-treated, the epithelium appears to be firmly adherent to the underlying ablated zone and may be very difficult to remove.

In the treatment of recalcitrant erosions, it is possibly both the removal of the 'abnormal' epithelium and basement membrane and the ablation of Bowman's membrane that are important for a successful outcome. The former results in regeneration of basal epithelial cells with the production of a new basement membrane, while latter will allow the epithelium to come into direct contact with stromal elements, stimulating the synthesis of new anchoring fibrils and hemidesmosomes.

Excimer laser technology, although expensive, is becoming more widely available due to the demand for refractive procedures. One of the potential benefits of this is the possibility of improving the treatment of recalcitrant recurrent corneal erosion. The success rate in such cases is high and the complications are very few. Further studies are now indicated to compare its effectiveness with established surgical procedures.

\section{J.M. is a consultant for Summit Technology.}

The authors acknowledge the Iris Fund for Prevention of Blindness for continued financial support in relation to both the purchase and maintenance of the laser and provision of a Research Fellowship for the principal investigator, D.P.S.O'B. The authors thank Mrs Ann Patmore for technical support and Sister Anne Welch and Mrs Judith Armstrong for clinical assistance. Finally, they thank Mrs June Krafft for her secretarial assistance.

Key words: Excimer laser, Recurrent erosion.

\section{REFERENCES}

1. Hansen E. Om den intermitterende keratitis vesiculosa neuralgica af traumatisk oprindsele. Hospital Stidende 1872;15:201-3.

2. Bronner A. On some cases of traumatic keratalgia. Trans Ophthalmol Soc UK 1889;9:89-94.

3. Reuss AV. Ueber recidiverende traumatische Erosionen der Hornhaut. Prag Med Wochenschr 1898;21:243-5.

4. Kauffmann E. Klinische Studien zur Frage der rezidivierenden Erosion. Klin Monastbl Augenheilkd 1907;45:202-10.

5. Peters A. Ueber traumatische Hornhauterkrandungen und ihre Beziehungen zum Herpes Cornea. Graefes Arch Klin Exp Ophthalmol 1904;57:93-137.

6. Thygeson P. Observations on recurrent erosion of the cornea. Am J Ophthalmol 1959;47:48-52.

7. Cogan GD, Donaldson DD, Kuwabara T, et al. Microcystic dystrophy of the corneal epithelium. Trans Am Ophthalmol Soc 1964;62:213-5.

8. Kauffman HE, Clower JW. Irregularities of Bowman's membrane. Am J Ophthalmol Soc 1966;61:227-30.

9. Goldman JN, Dohlman CH, Kravitt BA. The basement membrane of the human cornea in recurrent epithelial erosion syndrome. Trans Am Acad Ophthalmol Otolaryngol 1969;73:471-81.

10. Trobe JD, Laibson PR. Dystrophic changes in the anterior cornea. Arch Ophthalmol 1972;87:378-82.

11. Hykin PG, Foss AE, Pavesio C, Dart JKG. The natural history and management of recurrent corneal erosion: a prospective randomised trial. Eye 1994;8:35-40.

12. Hull DS, Hyndiuk RA, Chin GN, et al. Clinial experience with the therapeutic hydrophilic contact lens. Ann Ophthalmol 1975;7:555-62.
13. Mobilia EF, Foster CS. The management of recurrent corneal erosions with ultrathin lenses. Contact Intraocul Lens Med J 1978:4:25-9.

14. Buxton FN, Fox ML. Superficial epithelial keratectomy in the treatment of epithelial basement membrane dystrophy. Arch Ophthalmol 1983;101:392-5.

15. Mclean EN, MacRea SM, Rich LF. Recurrent erosion: treatment by anterior stromal puncture. Ophthalmology 1986:93:784-8.

16. Wood TO. Recurrent erosion. Trans Am Ophthalmol Soc 1984;82:850-98.

17. Wood TO, McLaughlin BJ. Recurrent erosion. Int Ophthalmol Clin 1988;28:83-93.

18. Gartry D, Kerr Muir M, Marshall J. Excimer laser treatment of corneal surface pathology: a laboratory and clinical study. Br J Ophthalmol 1991;75:258-69.

19. Marshall J, Trokel S, Rothery S, Schubert H. An ultrastructural study of corneal incisions induced by an excimer laser at $193 \mathrm{~nm}$. Ophthalmology 1985;92:749-58.

20. Marshall J, Trokel S, Rothery S, Krueger RR. A comparative study of corneal incisions induced by diamond and steel knives and two ultraviolet radiations from an excimer laser. Br J Ophthalmol 1986;70:482-501.

21. Puliafito CA, Steinert RF, Deutsch TF, Hillenkamp F, Dehm EJ, Alder CM. Excimer laser ablation of the cornea and lens: experimental studies. Ophthalmology 1985;92:741-8.

22. Marhshall J, Trokel S, Rothery S, Kreuger RR. Photoablative reprofiling of the cornea using an excimer laser: photorefractive keratectomy. Lasers Ophthalmol 1986; 1:21-48.

23. Sher NA, Bowers RA, Zabel RW, Frantz JM, Eiferman RA, Brown DC, et al. Clinical use of the $193 \mathrm{~nm}$ excimer laser in the treatment of corneal scars. Arch Ophthalmol 1991; 109:491-8.

24. Stark WJ, Chamon W, Kamp MT, Enger CL, Rencs EV, Gottsh JD. Clinical follow-up of $193 \mathrm{~nm}$ ArF excimer laser photokeratectomy. Ophthalmology 1992;99:805-12.

25. Fagerholm P, Fitzsimmons TD, Orndahl M. Ohman L, Tengroth B. Phototherapeutic keratectomy: long-term follow-up results in 166 treated eyes. Refract Corneal Surg 1993; (suppl)9:S76-80.

26. O’Brart DPS, Gartry DS, Lohmann CP, Patmore AL, Kerr Muir MG, Marshall J. Treatment of band keratopathy by excimer laser phototherapeutic keratectomy (PTK): surgical techniques and long term follow-up. $\mathrm{Br} \mathrm{J}$ Ophthalmol 1993;77:702-8.

27. Steinert RF, Puliafito CA. Excimer laser phototherapeutic keratectomy for a corneal nodule. Refract Corneal Surg 1990;6:352.

28. Dausch D, Landesz M, Klein R, Schroder E. Phototherapeutic keratectomy in recurrent corneal epithelial erosion. Refract Corneal Surg 1993;9:419-24.

29. Wolff E. Anatomy of the eye and orbit, 6th ed, revised by Last RJ. London: HK Lewis, 1968:36.

30. Lohmann CP, Gartry D, Kerr Muir M, Timberlake G, Fitzke F, Marshall J. Haze in photorefractive keratectomy: its origins and consequences. Laser Light Ophthalmol 1991; $4: 15-34$.

31. O'Brart DPS, Lohmann CP, Fitzke FE, Klonos G, Corbett MC, Kerr Muir MG, Marshall J. Disturbances in night vision after excimer laser photorefractive keratectomy. Eye 1994; in press.

32. Geggel J. Successful treatment of recurrent corneal erosion with Nd:YAG anterior stromal puncture. Am J Ophthalmol 1990;110:404-7.

33. Katsev DA, Kincaid MC, Fouraker BD, Dresner MS, Schanzlin DJ. Recurrent corneal erosion: pathology of corneal puncture. Cornea 1991;10:418-23.

34. Garty DS, Kerr Muir MG, Marshall J. Photorefractive keratectomy with an argon fluoride excimer laser: a clinical study. Refract Corneal Surg 1991:7:420-35. 
35. Seiler T, Holschbach A, Derse M, Jean B, Genth U. Complications of myopic photorefractive keratectomy with the excimer laser. Ophthalmology 1994;101:153-60.

36. SundarRaj N, Geiss M, Fantes F, et al. Healing of excimer laser ablated monkey corneas: an immunohistochemical evaluation. Arch Ophthalmol 1990;108:1604-10.
37. Marshall J, Trokel SL, Rothery S, Krueger RR. Long-term healing of the central cornea after photorefractive keratectomy using an excimer laser. Ophthalmology 1988;95: $1411-21$ 